\title{
Supernumerary kidneys: a clinical and radiological analysis of nine cases
}

\author{
Peter Rehder ${ }^{1 \dagger}$, Rafael Rehwald ${ }^{2,3 \dagger}$, Julia M. Böhm ${ }^{4}$, Astrid E. Grams ${ }^{5}$, Alexander Loizides ${ }^{4}$, Marco Pedrini $^{1}$, \\ Jannik Stühmeier ${ }^{1}$ and Bernhard Glodny ${ }^{4^{*}}$
}

\begin{abstract}
Background: A supernumerary kidney (SK) is an additional kidney with its own capsule and blood supply that is not fused with the ipsilateral kidney (IK). Because individual case reports indicate a high morbidity rate, the aim of this retrospective study was a detailed analysis of this rare anatomical variant.

Methods: Our systematic imaging-based search for SKs, conducted in the period from 2000 and to 2017, yielded 9 cases in total ( 5 men, 4 women; mean age: $51.8 \pm 22.8$ years).

Results: The SKs were observed on the right in six and on the left side in three cases. In six subjects (66\%) they were located caudal and in three cases (33\%) cranial to the ipsilateral kidney. Calculi were found in three (33\%) of the renal collecting systems. Five (56\%) of the SKs had hydronephrosis grade IV and one SK had recurrent pyelonephritis (11\%). Two of the ureters opened into the ipsilateral seminal vesicle (22\%). Two (22\%) SKs were functional but atrophic. Clinically relevant findings were made in 33\% of the IKs: atrophy $(n=2)$, calculi $(n=1)$, and reflux with recurrent pyelonephritis $(n=1)$; another $33 \%$ had anatomical anomalies without functional impairment. The correct diagnosis of a SK is possible using CT imaging in all subjects. The prevalence of SK based on CT imaging can be estimated to be 1:26750.
\end{abstract}

Conclusions: $\mathrm{CT}$ is the method of choice for visualizing SKs. The correct diagnosis is crucial in preventing dispensable surgical procedures and for providing optimal patient treatment and outcome.

Keywords: Supernumerary kidneys, Computed tomography, Renal variants, Diagnostic imaging, Duplex kidneys, Ureter fissus

\section{Background}

Supernumerary kidneys (SKs) are usually one [1], rarely two [2-5] additional kidneys, distinguished from the significantly more common duplex kidneys by the fact that they are not fused with the other kidney and have their own capsule and blood supply [1]. Most SKs are smaller than normal kidneys [6], but they can also be larger [1, 6, 7]. SKs are usually located caudal, less frequently cranial to the ipsilateral kidney [1]. While there is as yet no comprehensive description of the blood supply of SKs because of its high variability [1], the ureters of a SK tend to join with those of the ipsilateral kidney (IK) [1]. However, completely separate ureters draining into the bladder $[1,8]$, the vagina $[9]$, the

\footnotetext{
* Correspondence: bernhard.glodny@i-med.ac.at

†Peter Rehder and Rafael Rehwald contributed equally to this work.

${ }^{4}$ Department of Radiology, Medical University of Innsbruck, Anichstraße 35, 6020 Innsbruck, Austria

Full list of author information is available at the end of the article
}

vulva [10], the prostatic urethra, or into vesical or vaginal pouches [1] have also been described.

Supernumerary kidneys have no inherent clinical relevance [1]. They are- however- often accompanied by urolithiasis, pyonephrosis, infections or hydronephrosis $[1,6,11]$. Individual cases have also been reported in which an associated adenocarcinoma [12], a Wilms tumor [13] or a cyst [7] were observed. Furthermore, SKs can be subject to traumatic injuries [14].

Formerly, most cases of SKs were detected during surgery or autopsy $[6,15]$. Diagnostic methods such as retrograde pyelography [16], urography [12, 17-19], or angiography $[12,18-20]$ were less likely to lead to such a finding. Today, supernumerary kidneys are more frequently diagnosed using computed tomography (CT) [21], ultrasound, Tc- $99^{\mathrm{m}}$ MAG3 scintigraphy [22], Tc-

(c) The Author(s). 2019 Open Access This article is distributed under the terms of the Creative Commons Attribution 4.0 International License (http://creativecommons.org/licenses/by/4.0/), which permits unrestricted use, distribution, and reproduction in any medium, provided you give appropriate credit to the original author(s) and the source, provide a link to the Creative Commons license, and indicate if changes were made. The Creative Commons Public Domain Dedication waiver (http://creativecommons.org/publicdomain/zero/1.0/) applies to the data made available in this article, unless otherwise stated. 
$99^{\mathrm{m}}$ DTPA scintigraphy [23] or magnetic resonance imaging (MRI) [24].

One notable reason for the increased morbidity appears to arise from misinterpretations in the assessment of diagnostic procedures, in which SKs are not recognized as such. There may be no consequences [25], but this can at worst also lead to unnecessary interventions, such as biopsies [26] or surgery [27], including the risk of further complications [28].

The prevalence of SKs is unknown. There are only case reports of incidental findings of supernumerary kidneys, with a few exceptions of reports including two [1] or three cases $[29,30]$.

This study represents the yet largest case series, describing nine patients with supernumerary kidneys-the result of a systematic imaging-based assessment between 2000 and 2017. The aim of the present study was to estimate the frequency of SKs and to precisely describe and summarize both the anatomy and the clinical features of these patients for the first time.

\section{Methods}

A SK was defined as organ with a typically asymmetric collecting system to which a ureter is connected, having its own capsule and blood supply and not being fused with the other ipsilateral kidney, distinguishing it from duplex kidneys [1]. The ureter of the SK may not open into the vagina in order to rule out confusion with Gartner's duct cysts [31, 32], and no ureter may open into the presumed supernumerary kidney $[32,33]$. The SK must be connected to the lower urinary tract [32, 34] and it must not be filled with blood or mucus at the onset of puberty $[32,35]$.

A total of 461,500 radiological examinations of the abdomen (without duplicate examinations), performed between 2000 and 2017 at our institution were systematically reviewed for anomalies of the kidneys: 214,000 contrastenhanced CT scans acquired on spiral CT machines from different vendors (Genesis HiSpeed RP, QXi LightSpeed 4 Slice, LightSpeed 16, LightSpeed VCT 64, General Electric, W.I., USA; Somatom Sensation 4, 16 and 64 series, Somatom Definition Flash, Siemens AG, Erlangen, Germany), 31,500 MRI scans, performed on various systems (1.5 T Sonata, Symphony and Avanto, $3 \mathrm{~T}$ Magnetom Skyra, Siemens AG, Erlangen, Germany), 208,000 abdominal ultrasound examinations (HDI 5000, iU22, CX50 and EPIQ 7 ultrasound systems, Koninklijke Philips N.V., Best, the Netherlands; Xario 200, Aplio a550 and i800 series, Canon Medical Europe B.V., Zoetermeer, the Netherlands), as well as 8000 angiographies and urographies (Integris angiography unit, Koninklijke Philips N.V., Best, the Netherlands).

Most CT scans in patients with supernumerary kidneys were acquired after the intravenous application of iodinated contrast medium during a parenchymatous phase in $5 \mathrm{~mm}$ slice-thickness, while a urographic phase was almost always missing. All MRI examinations in which a supernumerary kidney was identified consisted of at least a $\mathrm{T}_{2}$-weighted sequence.

A significant part of the abdominal CT and MRI examinations was evaluated in the context of daily clinical routine. Additionally, the radiological reports of all included modalities were systematically screened for incidental findings of the urogenital tract, and the respectively identified imaging material carefully assessed. In a second step, every detected anomaly was independently re-evaluated and classified by both a senior board-certified radiologist (BG) and urologist (PR), resulting in nine cases of a SK beeing identified based on the inclusion criteria described (an organ with an asymmetric renal collecting system with an arising ureter, own capsule and blood supply and without fusion with the other kidney). A histopathological examination of the SK was available for four cases.

The renal anatomy of each identified SK has been comprehensively illustrated based on the imaging material available (Fig. 1), and additional coronal and sagittal $\mathrm{CT}$ and MRI reconstructions are presented for some patients in Fig. 2a-c, as these planes are considered particularly well suited to demonstrate supernumerary kidneys [36].

Descriptive statistics were performed using IBM SPSS Statistics for Windows, version 21 (IBM Corp., Armonk, N.Y., USA), with mean values and standard deviations given. For the statistical analysis, Fisher's exact test was used for categorical and the Mann-Whitney $U$ test for continuous variables. The sensitivity of the modalities was estimated under the assumption that kidneys can be reliably diagnosed using computed tomography [37]. The prevalence was determined based on the total number of patients examined between 2000 and 2017 with each imaging modality, respectively. A $p<0.05$ was considered to be statistically significant.

\section{Results}

Nine patients with a SK were identified; five men and four women (mean age $51.8 \pm 22.8$ years). The SKs were identified on the right in six cases and on the left in three cases ( $p=0.132$, Fisher's exact test), caudal to the IK in six cases (cases 1, 4, 5, 6, 7, and 9) and cranial in three cases (cases 2, 3, and 8). The supernumerary kidneys are illustrated in Fig. 1a-I. Figure 2a-c shows sectional images, as well as ostensive images of selected cases.

Three out of nine patients (cases 4, 6, and 9; 33\%) were clinically symptomatic due to the SK (infection and pain in case 4, pain in cases 6 and 9). The other cases were incidental findings (66\%). None of the patients had initially had a urological examination; in three cases, 


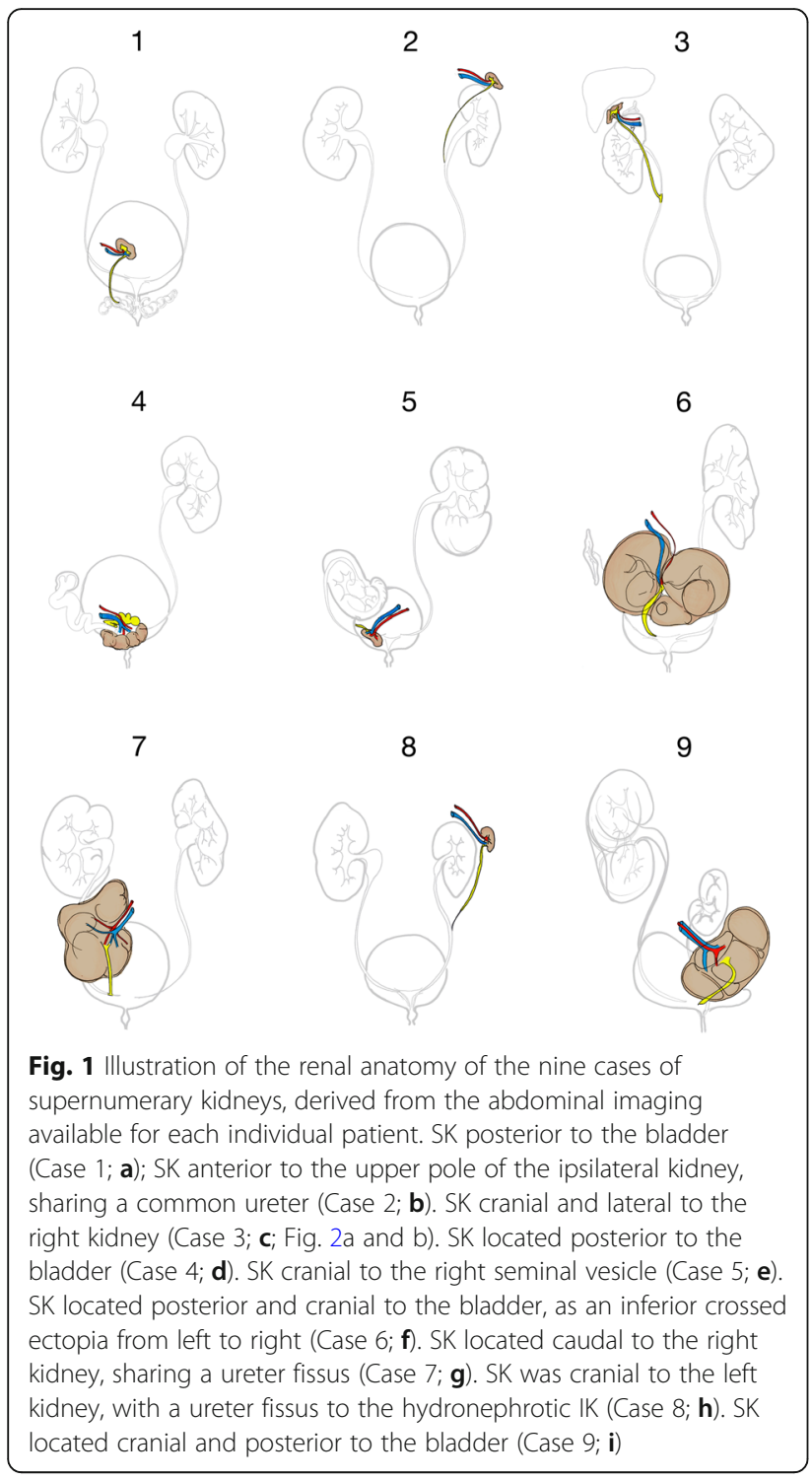

urology was consulted later. The working diagnoses for the referral to imaging are listed in Table 1.

In two patients, the diagnosis had initially been made based on imaging (cases 1 and 6), in two other patients, the SKs were only described without further interpretation (cases 2 and 8). The other cases were misdiagnosed as a mesenteric cyst (case 7), a metastasis (case 3), an abscess (case 4), a megaureter (case 9) or a unknown tumor (case 5) (Table 2). Thus, the correct diagnosis had initially been made in only $22 \%$ of the cases, no diagnosis in $22 \%$ and an incorrect diagnosis in $66 \%$ of the cases.

The initial imaging modality was CT in seven subjects $(78 \%)$ and ultrasound in the other two cases (cases 6 and 9; $22 \%$ ). A total of 28 CT scans (8 patients; range: $1-8$ ), 16 sonographies ( 6 patients; range $0-5), 12$ MRI scans (5 patients; range 0-6), 4 voiding cystourethrograms (3 patients; range 1-2), 2 PET-CT scans (2 patients; range 0-
1), 1 urography and one angiography (range $0-1$ ) has been performed. Retrospectively, all initially acquired CT scans $(100 \%)$, both PET-CT scans $(100 \%)$, three of five initial MRIs (60\%), and one of three voiding cystourethrographies (VCUG, 33\%) were sufficient to establish the correct diagnosis. A sensitivity of $100 \%$ was achieved with CT and PET-CT, 60\% with MRI and VCUG and 0\% with angiography and sonography. Specificity estimates as well as positive and negative predictive values could not reliably be obtained, as discussed below.

Due to the number of individual examinations performed between 2000 and 2017, the period prevalence rates of SKs were estimated to be 1:26750 based on the CT scans and 1:31500 based on MR imaging. All other examinations were either performed for diagnostic purposes or were follow-up examinations after the initial CT scans.

None of the SKs were normal. The two (22\%) still functional SKs (cases 3 and 5) were shrunken. Three of the collecting systems had calculi (cases 1, 2, and 8; 33\%). Five SKs had hydronephrosis grade IV (cases 4, 6, 7, 8, and 9; 56\%), and one of these suffered from recurrent pyelonephritis (case $4 ; 11 \%$ ). Two ureters opened into the ipsilateral seminal vesicle (cases 1 and 5; 22\%). The SK's were with $5.7 \pm$ $3.6 \mathrm{~cm}$ versus $9.2 \pm 1.7 \mathrm{~cm}$ smaller than the IKs $(p<0.05)$.

Five patients underwent medical procedures related to their SK. One non-functioning SK with calculi which has been observed for 12 years was finally removed during a prostatectomy (case 1 ). In case 4 , the patient presented externally with lower abdominal pain and fever. A hydronephrotic, orthotopic IK had been removed previously and the pyelonephritic SK in the small pelvis was misinterpreted to be an abscess. A vesicorectal fistula developed as a complication after the surgery. In case 5, imaging follow-up of the SK was planned, as a tumor was previously reported. The abdominal pain of patients 6 and 9 could be cured by surgical removal of their SKs.

Four out of the nine IKs were normal (cases 1, 2, 3, and $7 ; 44 \%$ ). Three were ectopic and located caudally in the pelvis (cases 5, 6, and 9; 33\%), one had calculi (case 8 ) and one had been removed because of recurrent pyelonephritis and vesicoureteral reflux (case 4). Four out of nine ipsilateral kidneys had a ureter fissus that branched to the SK (cases 2, 3, 7, and 8; 44\%). Two of the kidneys were atrophic (cases 6 and 8, 22\%). All contralateral kidneys were normal.

Three patients (33\%) presented with a spina bifida occulta of the 5th (cases 6 and 9) or 6th lumbar vertebral arch (case 5). No other deformities were found.

\section{Discussion}

The prevalence of supernumerary kidneys can be estimated to be 1:26750 with CT imaging. Supernumerary kidneys have been found more frequently located caudal than cranial to the ipsilateral kidney, and more often on 


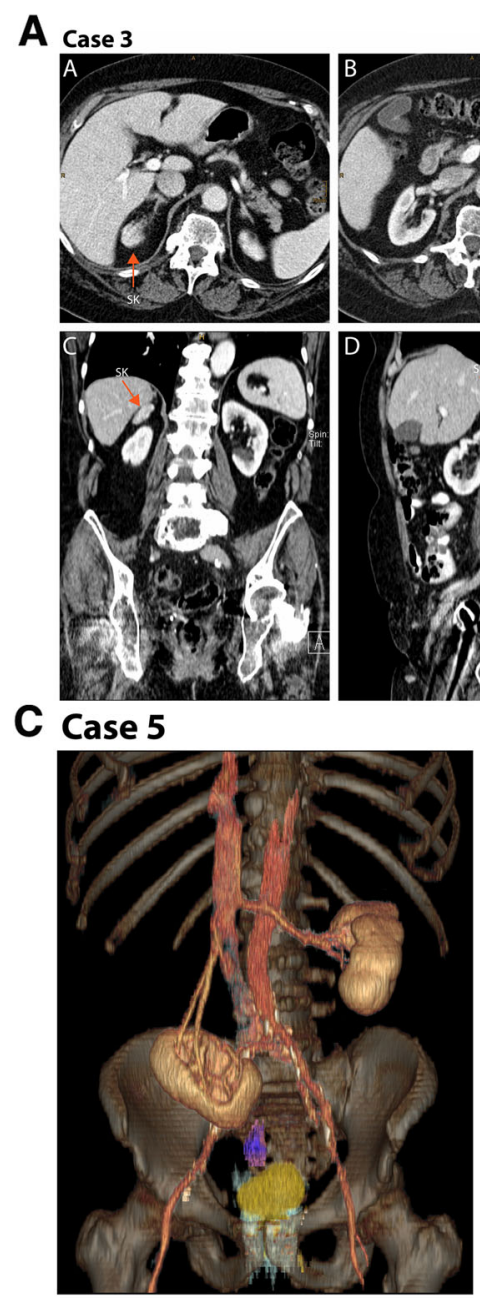

\section{Case 9}

B Case 6

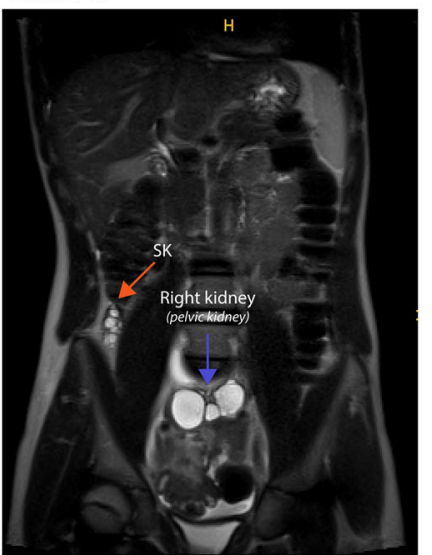

Case 7
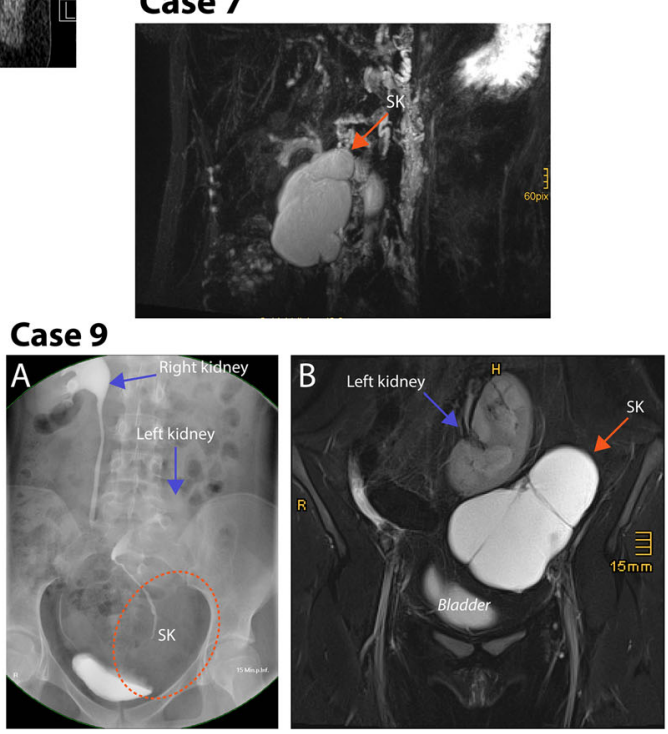

Fig. 2 Case 3: (a) Transversal contrast-enhanced CT of a supernumerary kidney (SK) on the right, located dorso-lateral and at the same level as the ipsilateral adrenal gland. The SK presents with the same attenuation as the contralateral kidney. $\mathbf{b}$ Transversal contrast-enhanced CT of the normal kidneys bilaterally. c Sagittal CT-reconstruction. SK located cranial to the normal kidney. d Coronal CT-reconstruction with SK located cranial to the normal kidney. Case 5: Coronal 3D volume rendering reconstruction of a contrast-enhanced CT, SK in violet, bladder in yellow. Case 6: $T_{2}$-weighted coronal image of the abdomen, showing the supernumerary kidney and the hydronephrotic right kidney (pelvic kidney). Case 7: $T_{2}$-weighted thick-slab semi-coronal image of the supernumerary kidney and the normal kidney. Case 9: (a) $T_{2}$-weighted coronal slice of the left kidney, the SK and bladder. (B) Intravenous pyelogram (15 min after i.v. contrast administration) depicting the right and left kidney as well as the supernumerary kidney as a mass and bladder

the right than on the left side. All SKs were either hydronephrotic, atrophic, or had calculi while only two were still functional (22\%). Three of the IKs (33\%) were atrophic, hydronephrotic, or had calculi. However, only one third of the patients suffered from clinical symptoms; they all had pain that was cured after successful nephrectomy. The other cases can be considered as incidental radiological findings. Based on the criteria of a retroperitoneal organ with its own blood supply and capsule and an asymmetrical collecting system [1], all SKs could be identified as such using computed tomography as the imaging modality of choice.
This study has some limitations to consider. A histological examination of the SK was only available for four of the nine cases (cases 1, 4, 6, and 9). Furthermore, while the CT scans were of generally high quality, they were not specifically modified for optimal visualization of the kidneys. The retrospective estimate of the total number of examinations evaluated is also subject to a certain degree of uncertainty. One argument for the reliability is the good agreement of the prevalence of 1 : 27000 estimated based on CT and of 1:31500 based on MR imaging. The validity of the data regarding the accuracy of the presented diagnostic measures is however 
Table 1 Clinical details of the 9 patients with supernumerary kidneys

\begin{tabular}{|c|c|c|c|c|c|c|c|c|c|}
\hline No. & Age group & $\begin{array}{l}\text { Initial reason } \\
\text { for radiological } \\
\text { examination }\end{array}$ & $\begin{array}{l}\text { Referred to } \\
\text { radiology by? }\end{array}$ & $\begin{array}{l}\text { Initial } \\
\text { modality }\end{array}$ & $\begin{array}{l}\text { Additional } \\
\text { modalities }\end{array}$ & $\begin{array}{l}\text { Correctly } \\
\text { diagnosed }\end{array}$ & $\begin{array}{l}\text { Initial diagnosis } \\
\text { reported }\end{array}$ & $\begin{array}{l}\text { Initial } \\
\text { diagnosis } \\
\text { to } \\
\text { surgery }\end{array}$ & Patient management \\
\hline 1 & Adult & $\begin{array}{l}\text { Pneumonia } \\
\text { and } \\
\text { gastrointestinal } \\
\text { bleeding }\end{array}$ & Pulmonology & CT & $\begin{array}{l}2 \text { CT scans } 1 \\
\text { Cystography }\end{array}$ & Yes & $\begin{array}{l}\text { SK; diagnosis } \\
\text { rejected } 12 \\
\text { years later. DD: } \\
\text { "tumor" }\end{array}$ & 12 years & $\begin{array}{l}\text { Watch-and-wait surgery } \\
12 \text { years later together } \\
\text { with prostatectomy }\end{array}$ \\
\hline 2 & Adult & Liver cirrhosis & Gastroenterology & CT & $\begin{array}{l}7 \mathrm{CT} \text { scans } \\
1 \text { MR scan }\end{array}$ & No & $\begin{array}{l}\text { Described, but } \\
\text { without } \\
\text { diagnosis or } \\
\text { interpretation }\end{array}$ & - & No consequence \\
\hline 3 & Adult & $\begin{array}{l}\text { Uterine } \\
\text { Carcinoma }\end{array}$ & Gynecology & CT & $\begin{array}{l}3 \text { CT scans } \\
6 \text { US exams }\end{array}$ & No & $\begin{array}{l}\text { Metastasis of } \\
\text { the adrenal } \\
\text { gland }\end{array}$ & - & No consequence \\
\hline 4 & Adult & $\begin{array}{l}\text { Urinary tract } \\
\text { infections }\end{array}$ & Surgery & CT & $\begin{array}{l}5 \text { CT scans } \\
4 \text { US exam } \\
2 \\
\text { Cystographies } \\
3 \text { MR scans }\end{array}$ & No & Abscess & 2 days & $\begin{array}{l}\text { Series of operations. } \\
\text { Complications: urinary } \\
\text { leakage; fistula to rectum } \\
\text { and urine bladder }\end{array}$ \\
\hline 5 & Adult & Lumbalgia & GP & $\mathrm{CT}$ & - & No & $\begin{array}{l}\text { Recurrence of a } \\
\text { presumably } \\
\text { resected tumor }\end{array}$ & - & Watch-and-wait \\
\hline 6 & Child & $\begin{array}{l}\text { Lower } \\
\text { abdominal pain }\end{array}$ & Pediatrics & US & $\begin{array}{l}1 \mathrm{CT} \\
2 \text { US exam } \\
1 \text { MR scan }\end{array}$ & Yes & SK & 11 years & $\begin{array}{l}\text { Resection of the } \\
\text { hydronephrotic SK and } \\
\text { ureter; shrunken IK } \\
\text { remained in situ }\end{array}$ \\
\hline 7 & Adult & $\begin{array}{l}\text { Tumor } \\
\text { palpated }\end{array}$ & Gastroenterology & $\mathrm{CT}$ & 6 MR scans & No & $\begin{array}{l}\text { Mesenterial } \\
\text { cyst or } \\
\text { lymphocele }\end{array}$ & - & No consequence \\
\hline 8 & Adult & $\begin{array}{l}\text { Aortic } \\
\text { dissection }\end{array}$ & Surgery & $\mathrm{CT}$ & $\begin{array}{l}2 \text { CT scans } \\
1 \text { US exam }\end{array}$ & No & $\begin{array}{l}\text { Described, but } \\
\text { without } \\
\text { diagnosis or } \\
\text { interpretation }\end{array}$ & - & No consequence \\
\hline 9 & Adolescent & $\begin{array}{l}\text { Inguinal hernia } \\
\text { and pain }\end{array}$ & Surgery & US & $\begin{array}{l}2 \text { US exams } \\
1 \\
\text { Cystography } \\
1 \text { Urography } \\
1 \text { MR scan }\end{array}$ & No & $\begin{array}{l}\text { Megaureter or } \\
\text { cyst }\end{array}$ & 17 years & Resection \\
\hline
\end{tabular}

Abbreviations: DD Differential diagnosis, IK Ipsilateral kidney, SK Supernumerary kidney, UF Ureter fissus, US Ultrasound

limited. Whereas the sensitivity of the different imaging modalities (100\% for CT and PET-CT, 60\% for MRI and VCUG, and $0 \%$ for angiography and sonography) can be considered reliable for at least in their magnitude, other markers of diagnostic accuracy-such as specificity, positive and negative predictive values as indicators of diagnostic effectiveness [38]-could not be obtained due to an unknown rate of true negative cases. Moreover, it has to be acknowledged that some of the STARD criteria have not been met by the present study [39]. The MRI and CT cohorts, for example, do at least partly differ and do not fully comprise of the same patients, whilst the readers of one modality were not blinded to the results and reports from other modalities. Finally, the number of patients is too limited to calculate confidence intervals.
While it was possible to make the diagnosis retrospectively in all of the CT scans, no supernumerary kidney was clearly identified by ultrasound, although the SKs were sonographically visualized in cases 6 and 9 and abdominal ultrasounds were available for $55 \%$ of the patients. Sonography thus appears to be not suitable for the reliable detection of SKs. In two cases in which MRI had been performed, the SK was not completely within the field of view. When fully scanned, it was possible to make the correct diagnosis. Only the PET-CT scan appears to allow the diagnosis to be made as reliably as CT imaging. It appears, that the main reason for an initially incorrect diagnosis in $78 \%$ of the cases is the relatively unknown nature of a SK which is not even considered as a differential diagnosis and that patients with 


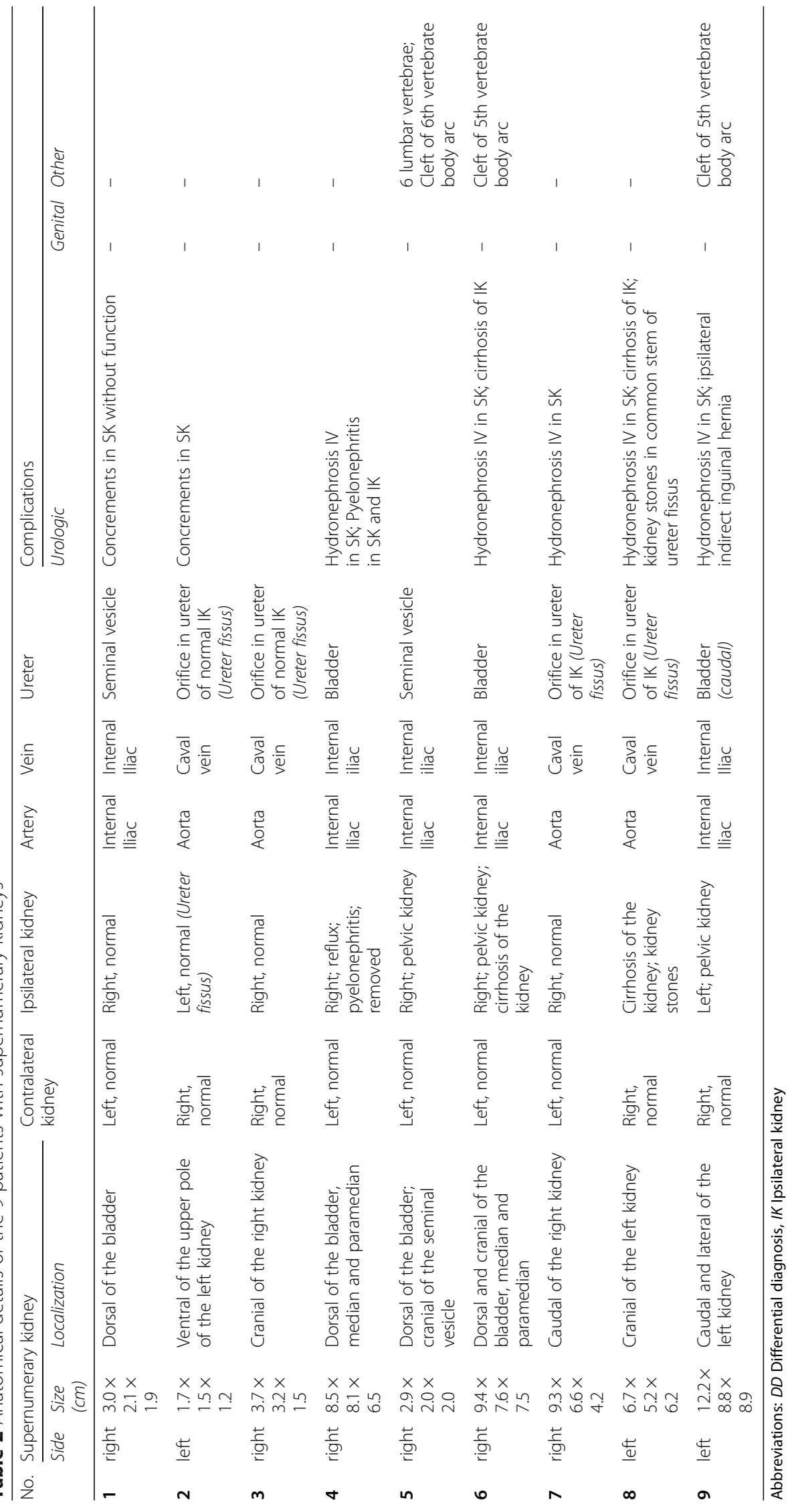


unclear retroperitoneal masses are generally rarely referred to urology.

It can therefore be argued that there is currently no universally established diagnostic approach to reliably diagnose supernumerary kidneys. Performing an intravenous pyelogram or CT urography (CTU) assumes an intention to diagnose, something that has been missing in most, if not all, cases presented in this work. Furthermore, such a radiological approach would still most likely not solely be expedient to secure a definitive diagnosis, as no urinary excretion was observed from most of the SKs. A MRI scan of the kidneys acquired on an up-to-date system and utilizing a heavily $\mathrm{T}_{2}$-weighted sequence would allow for a higher detection rate and a more precise diagnosis. However, a justified suspicion before referring a patient to MRI is nevertheless both from a clinical and economic perspective advantageous. Additionally, the appropriate area of interest in which the kidney is suspected should be carefully selected, as even in modern scanners the field of view (FOV) is often highly focused.

In all cases, the renal artery and the renal vein could be clearly identified, likewise the ureter, and the abdominal organs were separate from the IK in all cases, so that the criteria of Geisinger [1] were fulfilled. Therefore, a differential diagnosis of a Gartner's duct cyst combined with a Müllerian duct obstruction and ipsilateral renal dysgenesis [32] was not considered in any of the four female patients with SKs while, however, three such cases were identified but excluded.

While two of the SKs (cases 6 and 9) were larger than the other kidneys due to hydronephrosis grade IV, the other seven SKs were considerably smaller than regular kidneys. Only in cases 3 and 5 there no apparent cause other than atrophy as defined by Geisinger [1] is likely. Although the smallest supernumerary kidney was only $1.7 \times 1.5 \times 1.2 \mathrm{~cm}$ (case 2 ), it was not a so-called "Beiniere", a term first introduced by Neckarsulmer [40] in 1914 to describe a kidney that was attached to the upper pole of the adjacent kidney like a hood [1]. We found no case of such a non-functional "Beiniere" [1] without an excretory duct [41] or with a rudimentary collecting system, but non-functioning parenchyma [40] that was connected with the IK [1]. Instead, in case 2, a narrow bridge to the adjacent IK was observed, as described by Geisinger [1] in his second case, but with the difference that the third kidney was located lateral, not medial to the upper pole of the IK. A functional SK of normal size thus likely to be rare.

While all patients had a normal contralateral kidney, four on the right and five on the left side, $66 \%$ of the IKs were conspicuous. An ureter fissus (cases 2, 3, 7, and 8), or caudal ectopia (cases 5, 6, and 9) are not clinically relevant. However, two IKs were shrunken, one of them with calculi, and a third had to be surgically removed because of recurrent pyelonephritis. Therefore, and as suggested by Rubin [42], special attention needs to be given also to the normal ipsilateral kidney.

Concomitant deformities occurred in 33\% of the patients, consisting of fusion defects in the lumbosacral junctions which were clinically irrelevant and no further deformities were observed in other organ systems.

Detecting and correctly interpreting a supernumerary kidney by imaging is important for several reasons. Unnecessary procedures, as in case 1 , could be prevented, and even more importantly complications of dispensable surgical procedures, such as in case 4 , could be avoided, as the kidney should have been surgically removed in toto. The correct diagnosis is possible with a CT scan, and elaborate follow-ups would not be required. If there is no UF, the diagnosis can be confirmed by cystoscopy and verifying the presence of the ureter ostium. An accurate diagnosis is essential for providing an effective and successful therapy, which should ultimately consist of uretro-nephrectomy. This radical therapeutic approach is, however, only indicated if the kidney is clinically symptomatic. In conclusion, for the purpose of the most effective therapy, no generally valid treatment recommendations can be offered, except that each therapeutic decision should be tailored to the individual circumstances.

\section{Conclusion}

In summary, our results show that SKs occur with a prevalence of 1:26750. None of the SKs were normal, however only one third of the patients had clinical manifestations. Surgery is rarely indicated, but can cure the pain that is sometimes present. Supernumerary kidneys can be identified by CT using Geisinger's [1] criteria: a retroperitoneal organ with its own blood supply and own capsule and an asymmetric collecting system. In order to avoid unnecessary operations and the concomitant risk of complications, the correct diagnosis is of utmost importance for the individual patients.

\section{Abbreviations \\ CT: Computed tomography; CTU: Computed tomography urography; FOV: Field of view; IK: Ipsilateral kidney; MRI: Magnetic resonance imaging; PET: Positron emmision tomography; SK: Supernumerary kidney; UF: Ureter fissus; US: Ultrasound; VCUG: Voiding cystourethrography}

\section{Acknowledgements \\ N/A}

\section{Authors' contribution}

$P R, R R$ and $G B$ were the chief investigators of this study. PR, RR, JMB, AEG and GB conducted, designed and managed this study, acquired, analysed and interpreted the data, performed the literature search, wrote the final version of the manuscript and revised it critically. AL, MP and JS analysed and interpreted the data, contributed to the literature search and the final version of the manuscript and revised it critically. All authors reviewed and approved the final version of the manuscript. 


\section{Funding}

No funding was received for this study.

\section{Availability of data and materials}

In accordance with the relevant statutory and legal provisions, the data as used in this publication are available from the corresponding author on reasonable individual written request. However, no information potentially identifying any subjects from this study will be shared.

\section{Ethics approval and consent to participate}

This retrospective analysis was approved by the Ethics Committee of the Medical University of Innsbruck (Reference: AN2015-0196-352/4.16). Due to the retrospective design of this study, individual patient consent to be included in this investigation was waived by the institutional ethics committee.

\section{Consent for publication}

Due to the retrospective design of this study, no individual patient consent was required and all data used has been fully anonymized.

\section{Competing interests}

The authors declare that they have no competing interests to declare with regard to this study.

\section{Author details}

'University Hospital for Urology, Department of Surgery, Medical University of Innsbruck, Innsbruck, Austria. ${ }^{2}$ Department of Radiology, University of Cambridge, Cambridge, UK. ${ }^{3}$ Queen Square Institute of Neurology, University College London, London, UK. ${ }^{4}$ Department of Radiology, Medical University of Innsbruck, Anichstraße 35, 6020 Innsbruck, Austria. ${ }^{5}$ Department of Neuroradiology, Medical University of Innsbruck, Innsbruck, Austria.

Received: 8 February 2019 Accepted: 20 September 2019 Published online: 17 October 2019

\section{References}

1. Geisinger JF. Supernumerary kidney. J Urol. 1939;38(4):331-56.

2. Pintér $A B$, Schäfer J, Varró J. Two supernumerary kidneys with ureteral atresia. J Urol. 1982;127(1):119-20.

3. Shane JH. Supernumerary kidney with vaginal ureteral orifice. J Urol. 1942;47:344.

4. Saccone $A H, H$. B. Supernumerary kidney: report of a case and review of the literature. J Urol. 1934:31:711-20.

5. Budniok R, Suchowsky G. A case of bilateral supernumerary kidney and bilateral supernumerary ureter with extravesicular orifices a contribution on anomalies of the urinary tract. Z Urol. 1951;44(7):453-63.

6. Carlson HE. Supernumerary kidney: a summary of 51 reported cases. J Urol. 1950;64(2):224-9.

7. Wulfekuhler WV, Dube VE. Free supernumerary kidney: report of a case. $J$ Urol. 1971;106(6):802-4.

8. Fischer K, Rosenloecher K. Über einen Fall von dritter Niere mit selbstständigem Harnleiter. Zeitschrift für Urologische Chirurgie. 1925;17:61-6.

9. Headings DM, Palmer RE. Supernumerary kidney with ureter opening into vagina. Am J Surg. 1946;71:370-3.

10. Van den Bulcke C, Keutgen JM, Van Hees JN. Apropos of a case of supernumerary kidney with megaureter leading into the vulva. Acta Urol Belg. 1966;34(3):282-6

11. Costantino L. The supernumerary kidney. On a case Minerva Chirurgica. 1974;29(21):1132-5.

12. Fratkin LB, Johnson HW, Moscovich BB. Adenocarcinoma in supernumerary kidney. Can J Surg. 1963;6:195-8.

13. Wu JP, Garcia J. Supernumerary kidney with Wilms' tumor. Wis Med J. 1971; 70(10):211-6.

14. Ogreid PI, Bo O, Loovas J. Traumatic haematuria in supernumerany hydronephrotic kidney. A case report. Scand J Urol Nephrol. 1979;13(1):127-30.

15. Burgess SB. Supernumerary kidney: report of a case. Arch Pathol. 1960;69:154-7.

16. Stewart CM. True right supernumerary kidney diagnosed preoperatively. J Urol. 1949;61(2):327-32.

17. Jensenius $H$, Munck T. Supernumerary kidney with megalo-ureter; report of a case. Acta Chir Scand. 1955;109(1):20-5.

18. Hvezdoslav S. Eine klinisch diagnostizierte überzählige Niere. Zeitschrift für Urologie. 1956:49:343-9.
19. Browne MK, Glashan RW. Multiple pathology in a unilateral supernumerary kidney. Br J Surg. 1971:58(1):73-6.

20. Sasidharan K, Babu AS, Rao MM, Bhat HS. Free supernumerary kidney. Br J Urol. 1976;48(5):388

21. Khalda E, Singh GN, Mandal AK, Kumar R. Unilateral supernumerary kidney with contra lateral hydronephrosis-a rare case report. Australas Med J. 2014 7(5):213-7.

22. Kim N, Yung E, Katz DS. Supernumerary left kidney. Clin Nucl Med. 2004; 29(12):852-3.

23. Sy WM, Seo IS, Sze PC, Kimmel MA, Homs CJ, McBride JG, et al. A patient with three kidneys: a correlative imaging case report. Clin Nucl Med. 1999; 24(4):264-6

24. Moses KA, Kirsch AJ, Heiss EA, Gow KW. Supernumerary kidney in a term infant with VATER association. Am Surg. 2008;74(9):874-6.

25. Nouira K, Menif E, Nouira Y, Baccar S, Salem A, Horchani A, et al. Supernumerary kidney: a case report. Tunis Med. 2002;80(3):152-4

26. Bernik TR, Ravnic DJ, Bernik SF, Wallack MK. Ectopic supernumerary kidney, a cause of Para-aortic mass: case report and review. Am Surg. 2001;67(7):657-9.

27. Truc E, Grasset D, Balmes M. Giant hydronephrosis in a supernumerary kidney. J Urol Nephrol (Paris). 1962:68:356-8.

28. Yousef AK, Abu Khadra AL, Dajani AM. A pitfall in the diagnosis of supernumerary kidney. Br J Urol. 1991:67(1):100.

29. Macpherson RI. Supernumerary kidney: typical and atypical features. Can Assoc Radiol J. 1987:38(2):116-9.

30. Campbell MF. Anomalies of the kidney. In: Campbell MF, Harrison JH, editors. Urology. 2. 3rd ed. Philadelphia: W. B. Saunders Co.; 1970.

31. Gotoh T, Koyanagi T. Clinicopathological and embryological considerations of single ectopic ureters opening into Gartner's duct cyst: a unique subtype of single vaginal ectopia. J Urol. 1987;137(5):969-72.

32. Sheih CP, Liao YJ, Hung CS, Huang TS, Li YW. Duplex kidney, Gartner's duct cyst and ipsilateral Mullerian duct obstruction. J Urol. 1998;159(6):2120-1.

33. Gotoh T, Morita H, Tokunaka S, Koyanagi T, Tsuji I. Single ectopic ureter. J Urol. 1983;129(2):271-4.

34. Sheih CP, Hung CS, Wei CF, Lin CY. Cystic dilatations within the pelvis in patients with ipsilateral renal agenesis or dysplasia. J Urol. 1990;144(2 Pt 1):324-7.

35. Sheih CP, Li YW, Chen WL, Chang CH, Hung CS. Unilateral occlusion of duplicated mullerian ducts associated with ipsilateral Gartner's duct cyst: report of 3 cases. J Urol. 1993;149(3):543-5.

36. Chien JC-W, Chan WP. Bilateral Supernumerary Kidney. J Korean Med Sci. 2016:31(5):822-3.

37. Schlunt LB, Harper JD, Broome DR, Baron PW, Watkins GE, Ojogho ON, et al. Improved detection of renal vascular anatomy using multidetector $\mathrm{CT}$ angiography: is 100\% detection possible? J Endourol. 2007;21(1):12-7.

38. Simundic AM. Measures of diagnostic accuracy: basic definitions. EJIFCC. 2009;19(4):203-11

39. Ames A 3rd. CNS energy metabolism as related to function. Brain Res Brain Res Rev. 2000;34(1-2):42-68

40. Neckarsulmer K. Über Beinieren. Berliner klinische Wochenschrift. 1914:61: 1641-3.

41. Cobb F, Giddings HG. VII. Supernumerary kidney subject of Cystadenoma: report of a case verified by operation. Ann Surg. 1911;53(3):367-72.

42. Rubin JS. Supernumerary kidney with aberrant ureter terminating externally. J Urol. 1948:60(3):405-8.

\section{Publisher's Note}

Springer Nature remains neutral with regard to jurisdictional claims in published maps and institutional affiliations.

Ready to submit your research? Choose BMC and benefit from

- fast, convenient online submission

- thorough peer review by experienced researchers in your field

- rapid publication on acceptance

- support for research data, including large and complex data types

- gold Open Access which fosters wider collaboration and increased citations

- maximum visibility for your research: over $100 \mathrm{M}$ website views per year

At BMC, research is always in progress.

Learn more biomedcentral.com/submission 